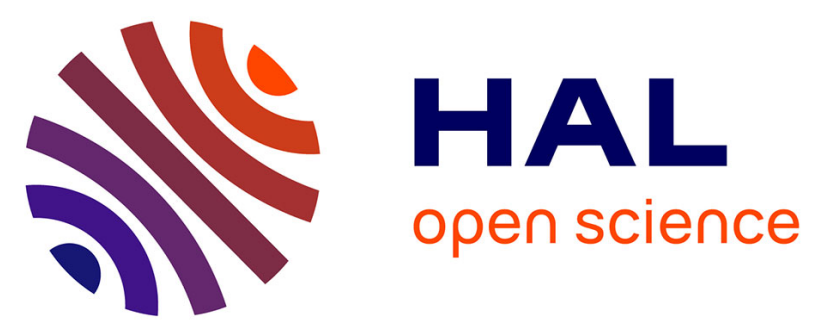

\title{
Efficiency of physiotherapy with Caycedian Sophrology on children with asthma: A randomized controlled trial
}

Huguette Romieu, Francoise Charbonnier, Dora Janka, Aymeric Douillard, Valérie Macioce, Kathleen Lavastre, Hamouda Abassi, Marie-Catherine Renoux, Thibault Mura, Pascal Amedro

\section{To cite this version:}

Huguette Romieu, Francoise Charbonnier, Dora Janka, Aymeric Douillard, Valérie Macioce, et al.. Efficiency of physiotherapy with Caycedian Sophrology on children with asthma: A randomized controlled trial. Pediatric Pulmonology, 2018, 53 (5), pp.559-566. 10.1002/ppul.23982 . hal-01796124

\section{HAL Id: hal-01796124 \\ https://hal.umontpellier.fr/hal-01796124}

Submitted on 22 Jan 2020

HAL is a multi-disciplinary open access archive for the deposit and dissemination of scientific research documents, whether they are published or not. The documents may come from teaching and research institutions in France or abroad, or from public or private research centers.
L'archive ouverte pluridisciplinaire HAL, est destinée au dépôt et à la diffusion de documents scientifiques de niveau recherche, publiés ou non, émanant des établissements d'enseignement et de recherche français ou étrangers, des laboratoires publics ou privés. 


\title{
Efficiency of physiotherapy with Caycedian Sophrology on children with asthma: A randomized controlled trial
}

\author{
Huguette Romieu $^{1}$ | Françoise Charbonnier ${ }^{1}$ | Dora Janka MD ${ }^{1}$ \\ Aymeric Douillard PhD ${ }^{2}$ | Valérie Macioce ${ }^{2}$ | Kathleen Lavastre ${ }^{1}$ | \\ Hamouda Abassi $^{1,4}$ | Marie-Catherine Renoux MD ${ }^{1}$ | Thibault Mura MD, PhD $^{2,5}$ | \\ Pascal Amedro MD, $\mathrm{PhD}^{1,3,4}$
}

${ }^{1}$ Department of Pediatric Cardiology and Pulmonology, University Hospital, Montpellier, France

${ }^{2}$ Department of Epidemiology and Clinical Research, University Hospital, Montpellier, France

${ }^{3}$ Physiology and Experimental Biology of Heart and Muscles Laboratory-PHYMEDEXP, UMR CNRS 9214-INSERM U1046, University of Montpellier,

Montpellier, France

${ }^{4}$ Self-Perceived Health Assessment Research Unit, EA3279, Department of Public Health, Mediterranean Medical School, Marseille, France

${ }^{5}$ INSERM U1061, University of Montpellier, Montpellier, France

\section{Correspondence}

Pascal Amedro, MD, PhD, Department of Pediatric Cardiology and Pulmonology Department, Montpellier University Hospital, 371 Avenue du Doyen Giraud, 34295 Montpellier, France.

Email: p-amedro@chu-montpellier.fr

Funding information

Ministère des Affaires Sociales et de la Santé,

Grant number: PHRIP 2012

\section{Abstract}

Background: Asthma is the most common chronic disease in pediatrics. Along with the usual drug therapy using corticosteroids and bronchodilators, some interest has been shown for adjuvant therapies, such as sophrology. However, the level of evidence for non-pharmaceutical therapies in asthma remains low, especially in children. This study aimed to assess whether in children with asthma, peak expiratory flow (PEF) improved more after a sophrology session alongside standard treatment than after standard treatment alone.

Methods: We carried out a prospective randomized controlled clinical trial among 74 children aged 6-17 years old, hospitalized for an asthma attack. Group 1: conventional treatment (oxygen, corticosteroids, bronchodilators, physiotherapy) added to one session of sophrology. Group 2: conventional treatment alone. The primary outcome was the PEF variation between the initial and final evaluations $\left(\mathrm{PEF}_{2}-\mathrm{PEF}_{1}\right)$.

Results: Demographic and clinical characteristics were similar in both groups at baseline. Measures before and after the sophrology session showed that the PEF increased by mean $30 \mathrm{~L} / \mathrm{min}$ in the sophrology group versus $20 \mathrm{~L} / \mathrm{min}$ in the control group $(P=0.02)$. Oxygen saturation increased by $1 \%$ versus $0 \%(P=0.02)$ and the dyspnea score with visual analogue scale improved by two points point $(P=0.01)$. No differences were observed between the two groups in terms of duration of hospitalization, use and doses of conventional medical treatment (oxygen, corticosteroids, and bronchodilators), and quality of life scores. 
Conclusions: Sophrology appears as a promising adjuvant therapy to current guideline-based treatment for asthma in children.

\section{KEYWORDS}

asthma, peak expiratory flow, pediatrics, physiotherapy, sophrology

\section{1 | INTRODUCTION}

Asthma is the most prevalent chronic disease in pediatrics, physiologically defined as a respiratory discomfort at expiration with inflammation of the bronchial epithelium, bronchospasm, and bronchial hyperactivity. Along with the usual drug therapy using corticosteroids and bronchodilators, many adjuvant therapies have been developed for asthma treatment. Although not consensual, respiratory physiotherapy is sometimes used in asthmatic patients, ${ }^{1}$ sometimes improving their quality of life. ${ }^{2}$ In children, drainage techniques vary from one, team to another. ${ }^{3}$ Other adjuvant therapies have also been used in asthma, such as hypnosis, ${ }^{4,5}$ relaxation, ${ }^{6-11}$ massages, ${ }^{12}$ group sessions with alternative therapies, ${ }^{13}$ and sophrology. ${ }^{14-16}$ These techniques focus on the psychological factors contributing to asthma attacks. $^{17-27}$

However, the scientific validation of these adjuvant therapies' efficacy has been extremely lacking. Long et $\mathrm{al}^{28}$ suggested that stress management techniques could improve respiratory function. Similarly, Alexander et $\mathrm{al}^{11}$ showed an increase of $22 \mathrm{~L} / \mathrm{min}$ in peak expiratory flow (PEF) after a relaxation session in asthmatic children, while the PEF decreased in the control group.

Sophrology is based on breathing, which is the only vital function that is automatic and can become conscious at any time. It comes from ancient Greek $\sigma \omega \zeta$ ("harmony,") $\varphi \rho \eta v$ ("mind"), and - $\lambda$ oүia ("study/ science"). Therefore, sophrology is the "study of the consciousness in harmony." Professor Alfonso Caycedo, a Colombian neuro-psychiatrist, developed the method in the 1960's, through his personal, and professional experiences. He presented in 1970 at the first International Sophrology Conference as an attempt to scientifically study the human consciousness, both as a philosophy and a way of life, as well as a therapy and a personal development technique. Pr Caycedo stated: "sophrology is learning to live." This healthcare philosophy is based on the study of human consciousness and of the relation between body and mind. It requires a structured method consisting in very practical physical and mental exercises, using techniques such as concentration, deep breathing, relaxation, visualization, and simple movements. Sophrology is more and more used as an adjuvant therapy to treat pain and/or anxiety in oncology, ${ }^{29,30}$ geriatrics, ${ }^{31}$ obstetrics, ${ }^{32,33}$ and dentistry. ${ }^{34}$ The randomized controlled trial from Constant et al ${ }^{35}$ found a positive impact of sophrology on non-invasive ventilation tolerance in adult patients with acute respiratory failure.

However, no scientific evidence is available regarding the efficiency of sophrology in children with asthma. Yet, during an asthma attack, children are stressed, in pain, tense, or simply uncomfortable.

This study aimed to assess whether, in children with asthma, PEF improved more following a sophrology session alongside standard treatment, than after standard treatment alone.

\section{2 | METHODS}

\section{1 | Study design and population}

This open-label randomized controlled trial was carried out in the tertiary care pediatric pulmonology Department of Montpellier University Hospital, France. All children aged 6-17 years, who were hospitalized for an asthma attack between November 2013 and March 2016, were assessed for eligibility. An asthma attack includes several signs: severe shortness of breath, chest tightness or pain, coughing or wheezing, low PEF values, and symptoms that fail to respond to use of a quick-acting (rescue) inhaler. Children with severe complications requiring intensive care unit transfer were not eligible. We did not approach eligible patients when logistic problems would compromise the research (hospitalization during the week-end, both sophrologists unavailable).

All included patients were randomized, into either the sophrology group or into the control group.

\section{2 | Formal aspects}

The study was conducted in compliance with the Good Clinical Practices protocol and Declaration of Helsinki principles. It was approved by the South Mediterranean IV Ethics Committee (2013A00581-44) and registered on ClinicalTrials.gov (NCT02114398). Informed consent was obtained from all parents.

\section{3 | Interventions}

In both groups, a physiotherapy session was performed in the morning by a physical therapist of our department who was not a sophrologist. In the sophrology group, a 1-h sophrology session was performed after the physiotherapy session. In order to limit the variability and subjectivity inherent in the sophrology technique, two different sophrologists (HR, FC) were in charge of the sessions according to their work schedule, and neither of them participated in the outcomes measurements. Both interventions (sophrology and physiotherapy) occurred on the day following the admission. 
The physiotherapy session lasted about $30 \mathrm{~min}$. After a bronchial auscultation, upper airways were de-obstructed with a physiological saline solution, when necessary. Then, directed ventilation (breathing exercises) was performed to improve the respiratory mechanics, followed, when required, by a bronchial drainage to evacuate secretions, with more or less help with the expectoration. The session ended with therapeutic education for appropriate use of the peak flow meter, asthma attack management, better exhaling, good adherence to medication treatments, and using inhalers.

The sophrology session lasted about $1 \mathrm{~h}$. The first part of the session, lasting about $15 \mathrm{~min}$, started with a discussion ("pre-sophronic dialogue") aimed at creating a climate of confidence. It included a brief presentation of sophrology and questions to the patient about his or her tastes, interests and activities. Then the main part of the session, of approximately $30 \mathrm{~min}$, used a slow and monotone-directed speech, leading the patient to a level between awakening, and sleep ("sophroliminal level"). This relaxation session aimed at facilitating "letting go," focusing on body sensations, and improving the well-being ("sophronization of vital base"). The techniques were adapted to the child's age, availability, and fatigue. Lastly, the session ended with a final discussion ("post-sophronic dialogue"), putting into words the different sensations felt without any judgment or interpretation ("pheno-description").

\section{4 | Randomization}

Randomization was carried out using a computer-generated list of random numbers with permuted-block, 1:1 ratio, varying block sizes, and stratification by age (6-11 and 12-17 years) and asthma severity (intermittent/mild persistent and moderate persistent/severe persistent). Allocation concealment was achieved by a centralized randomization procedure through an electronic case-report form.

\section{$2.5 \mid$ Outcomes}

\subsection{1 | Peak expiratory flow (PEF)}

The PEF is a primary tool used in assessing asthma attacks and monitoring airway changes in children above the age of $5 .^{36}$ The PEF was measured with a peak flow meter. All children received the same therapeutic education and all measurements were performed under the supervision of a trained physical therapist. The PEF value was directly indicated by the position of the ruler in the meter. Three measures were systematically taken, and the highest value was recorded. The percentage of predicted value was calculated using pediatric reference PEF values. ${ }^{37}$

The PEF was measured in both groups, first in the morning before the physiotherapy session $\left(\mathrm{PEF}_{1}\right)$ and then in the afternoon, $6 \mathrm{~h}$ later $\left(P E F_{2}\right)$. The primary outcome was the PEF variation between the initial and final evaluations $\left(\mathrm{PEF}_{2}-\mathrm{PEF}_{1}\right)$.

\subsection{2 | Visual analogue scale (VAS)}

The general state of the child was assessed using a face VAS with values from 0 (indicating very well) to 10 (indicating very bad), and answering five questions regarding physical health, fatigability, bronchial obstruction, dyspnea, and coughing. ${ }^{38}$ A physical therapist measured the VAS for each question, first in the morning before the physiotherapy session $\left(\mathrm{VAS}_{1}\right)$ and then in the afternoon, $6 \mathrm{~h}$ later $\left(V S_{2}\right)$. For each question, variation between the initial and final evaluations $\left(\mathrm{VAS}_{2}-\mathrm{VAS}_{1}\right)$ was measured.

\subsection{3 | Quality of life}

Quality of life was assessed before discharge from the hospital using the generic PedsQL questionnaire, with ratings by the children themselves, and by their parents (proxy-version). ${ }^{39}$ This instrument evaluates health-related quality of life in four dimensions (physical functioning, emotion functioning, social functioning, and school functioning). Each item uses a five-point Likert scale from 0 (never) to 4 (almost always). Items are reverse-scored and linearly transformed to a 0-100 scale, with higher scores indicating a better QoL.

After translation and cultural adaptation, the psychometric properties of the French version of the PedsQL appeared to be acceptable. $^{40}$ The French self- and proxy-versions versions of the questionnaire were used for various age groups: $5-7,8-12$, or 12-18 years.

\subsection{4 | Other clinical characteristics}

Asthma severity was categorized into four classes, and an asthma control level defined by the GINA guidelines (www.ginasthma.org) was collected at baseline. ${ }^{41}$ Asthma control was assessed using the asthma control test $(A C T)$, with versions adapted to children 11 years of age or younger, and to children 12 years or older. ${ }^{42,43}$

We collected oxygen saturation readings $\left(\mathrm{SpO}_{2}\right)$, hospitalization duration, oxygen flow (L/min), overall oxygen consumption during hospitalization (oxygen flow $\times$ delivery time), and asthma treatments (beta2-adrenergic agonists, corticosteroids) during hospitalization.

The families of all children hospitalized for asthma attack in our department are offered to participate in a therapeutic education group session, usually one month after hospital discharge. As part of this clinical trial, we collected this information about the actual participation in this education program.

\subsection{Sample size and statistical analysis}

To calculate the sample size, we hypothesized that the PEF would increase by $5 \%$ (standard deviation $12 \%$ ) in the control group and by $12 \%$ in the sophrology group. ${ }^{11}$ With a power of $80 \%$ and a bi-lateral alpha risk of $5 \%$, we planned to include 37 children in each group.

Quantitative variables were described with means and standard deviation or median and inter-quartile range, and qualitative variables were described with frequencies. Quantitative variables were compared with the parametric Student's $t$-test when the distribution was Gaussian and with the Mann-Whitney test otherwise. Qualitative variables were compared with the Chi-square test or Fisher's exact test, as appropriate. The analysis of our primary 
and secondary endpoints was supplemented by a multivariate analysis using a logistic regression model adjusting for clinical severity, age, and gender.

Analyses were performed in accordance with the intention-totreat principle. The two-sided significance level was 0.05. The SAS version 9 (SAS Institute, Cary, NC) was used.

\section{3 | RESULTS}

\section{1 | Study participants}

During the study period, 169 children aged 6-17 years old were hospitalized for an asthma attack in our department. Twelve children were not eligible because of complications requiring intensive care unit transfer. Because of the logistic issues mentioned before, 145 children were not approached to participate in the study. Two families refused to participate. A total of 74 children were included and randomized in the sophrology $(N=37)$ or control group $(N=37)$. All of them received the allocated treatment and had PEF measurements before and after the intervention. Patients' characteristics at baseline are described in Table 1. The two groups did not differ in any of the measured demographic and clinical variables, especially asthma severity, and control levels.

\subsection{Clinical endpoints variation}

Variations in clinical endpoints between the initial and final evaluations are shown in Table 2. PEF, dyspnea VAS level, and oxygen saturation improved significantly in the sophrology group compared to the control group (Figure 1). Variations in heart rate and respiratory rate did not differ between groups. Adjusting for clinical severity, age, and gender did not change the results. Patients of the sophrology group had a two-times greater chance of reaching a $30-\mathrm{L} / \mathrm{min}$ increase in $\mathrm{PEF}$ (adjusted odd ratio (OR): $1.9 ; 95 \%$ confidence interval $(\mathrm{Cl}): 1.0-3.7 ; P=0.05)$ and a $2 \%$ increase in oxygen saturation (adjusted $\mathrm{OR}: 2.2 ; 95 \% \mathrm{Cl}: 1.1-4.2 ; P=0.02$ ), but no improvement was found for heart rate, and respiratory rate.

\section{3 | Other clinical outcomes}

The sophrology group and the control group did not differ in terms of mean length of hospital stay ( $2.78 \pm 1.37$ days vs $2.73 \pm 1.77$ days, $P=0.53$, respectively) and overall median consumption of oxygen $(1.57[0.5-4] \mathrm{L} / \mathrm{min}$ vs $1.75[0.5-5] \mathrm{L} / \mathrm{min}, P=0.97$, respectively). Consumption of beta2-adrenergic agonists, and corticosteroids during hospitalization did not differ between groups, whatever the form used. Median consumption of salbutamol in sophrology and control groups was $55 \mathrm{mg}$ (interquartile range 32-85) and $50 \mathrm{mg}$ (30-100),

TABLE 1 Baseline characteristics of study participants

\begin{tabular}{|c|c|c|c|c|}
\hline & $N$ & Sophrology group & $N$ & Control group \\
\hline Gender (boys) & 37 & $23(62)$ & 37 & $22(59)$ \\
\hline Age (years) & 37 & $9.2(2.8)$ & 37 & $9.8(2.7)$ \\
\hline Height $(\mathrm{cm})$ & 37 & $132.9(15.6)$ & 37 & $138.7(16.5)$ \\
\hline Weight (kg) & 37 & $32.8(15.0)$ & 37 & $34.6(16.7)$ \\
\hline Asthma severity & 37 & & 37 & \\
\hline Intermittent/mild & & $31(84)$ & & $30(81)$ \\
\hline Moderate persistent/severe persistent & & $6(16)$ & & $7(19)$ \\
\hline Asthma control & 37 & $17.7(5.0)$ & 34 & $17.5(4.8)$ \\
\hline Heart rate $(\mathrm{bpm})$ & 37 & $113.4(16.9)$ & 37 & $118.1(16.7)$ \\
\hline Respiratory rate (cycle/min) & 37 & $23.8(6.4)$ & 37 & $25.3(6.8)$ \\
\hline Systolic blood pressure $(\mathrm{mmHg})$ & 34 & $109.0(11.0)$ & 34 & $111.0(10.4)$ \\
\hline Diastolic blood pressure $(\mathrm{mmHg})$ & 34 & $58.2(7.3)$ & 34 & $60.8(8.2)$ \\
\hline PEF (L/min) & 37 & $162.2(64.8)$ & 37 & $184.7(77.1)$ \\
\hline Percentage of predicted PEF (\%) & 37 & $71.4(21.3)$ & 37 & $72.4(24.0)$ \\
\hline $\mathrm{SpO} 2(\%)$ & 36 & $96.4(1.9)$ & 36 & $96.6(1.8)$ \\
\hline \multicolumn{5}{|l|}{ VAS } \\
\hline Physical health & 37 & $1.7(1.9)$ & 37 & $2.0(2.4)$ \\
\hline Fatigability & 37 & $2.6(2.6)$ & 37 & $3.4(3.0)$ \\
\hline Bronchial obstruction & 37 & $3.2(2.6)$ & 37 & $3.5(2.9)$ \\
\hline Breathlessness/dyspnea & 37 & $2.8(2.6)$ & 37 & $2.4(2.6)$ \\
\hline Coughing & 37 & $3.5(2.5)$ & 37 & $3.6(2.8)$ \\
\hline
\end{tabular}


TABLE 2 Variations in clinical endpoints between initial and final evaluations

\begin{tabular}{|c|c|c|c|c|c|}
\hline Variations (final-baseline) & $N$ & Sophrology group median (Q25; Q75) & $N$ & Control group median (Q25; Q75) & P-value \\
\hline PEF (L/min) & 37 & $30(15 ; 50)$ & 37 & $20(0 ; 30)$ & 0.02 \\
\hline $\mathrm{SpO} 2(\%)$ & 36 & $1(0 ; 3)$ & 36 & $0(0 ; 3)$ & 0.02 \\
\hline Oxygen flow (L/min) & 4 & $-1(-1.5 ;-0.3)$ & 6 & $-0.3(-0.5 ; 0.8)$ & 0.09 \\
\hline Heart rate (bpm) & 37 & $-1(-10 ; 4)$ & 36 & $-6(-16 ;-1.5)$ & 0.09 \\
\hline Respiratory rate (cycle/min) & 37 & $0(-4 ; 2)$ & 35 & $-2(-4 ; 4)$ & 0.67 \\
\hline \multicolumn{6}{|l|}{ VAS } \\
\hline Physical health & 37 & $-1(-2 ; 0)$ & 37 & $0(-2 ; 0)$ & 0.27 \\
\hline Fatigability & 37 & $0(-2 ; 0)$ & 37 & $0(-2 ; 0)$ & 0.78 \\
\hline Bronchial obstruction & 37 & $-2(-4 ; 0)$ & 37 & $0(-4 ; 0)$ & 0.14 \\
\hline Breathlessness/dyspnea & 37 & $-2(-4 ; 0)$ & 37 & $0(-2 ; 0)$ & 0.01 \\
\hline Coughing & 37 & $-2(-4 ; 0)$ & 37 & $-2(-2 ; 0)$ & 0.44 \\
\hline
\end{tabular}

PEF, peak expiratory flow; $\mathrm{SpO}_{2}$, oxygen saturation; bpm, beats per minute; VAS, visual analogue scale (0-well-10-bad).

Significant $P$ values $<0.05$ are marked in bold.

respectively, for nebulizers $(P=0.95)$ and $1000 \mathrm{mg}(500-1200)$ and $675 \mathrm{mg}$ (500-1200), respectively, for inhalers $(P=0.55)$. The median consumption of prednisone was $20 \mathrm{mg}$ per day (interquartile range 20$50 \mathrm{mg})$, in both groups $(P=0.87)$.

One month after hospital discharge, we found no significant difference in terms of participation in our asthma education program: $35 \%$ of the children in the sophrology group and $45 \%$ in the control group $(P=0.8)$.

\section{4 | Quality of life}

The quality of life scores were not significantly different between the sophrology and the control groups, overall $(72.6 \pm 12.1$ vs $73.4 \pm 13.7$,
$P=0.8$, respectively), in each sub-group by age (5-7, 8-12, and 13-18 years old), and in self and proxy-reports (Table 3 ).

\section{DISCUSSION}

This study is one of the very few randomized controlled pediatric clinical trials evaluating a non-pharmacologic therapy in asthma, and the first one involving sophrology.

We intended to objectively assess the impact of sophrology on asthma and successfully included the expected number of 74 children planned in the study design. Indeed, the enthusiasm of families to participate in this study was important and almost none refused to participate. Many participants were in fact disappointed not to be
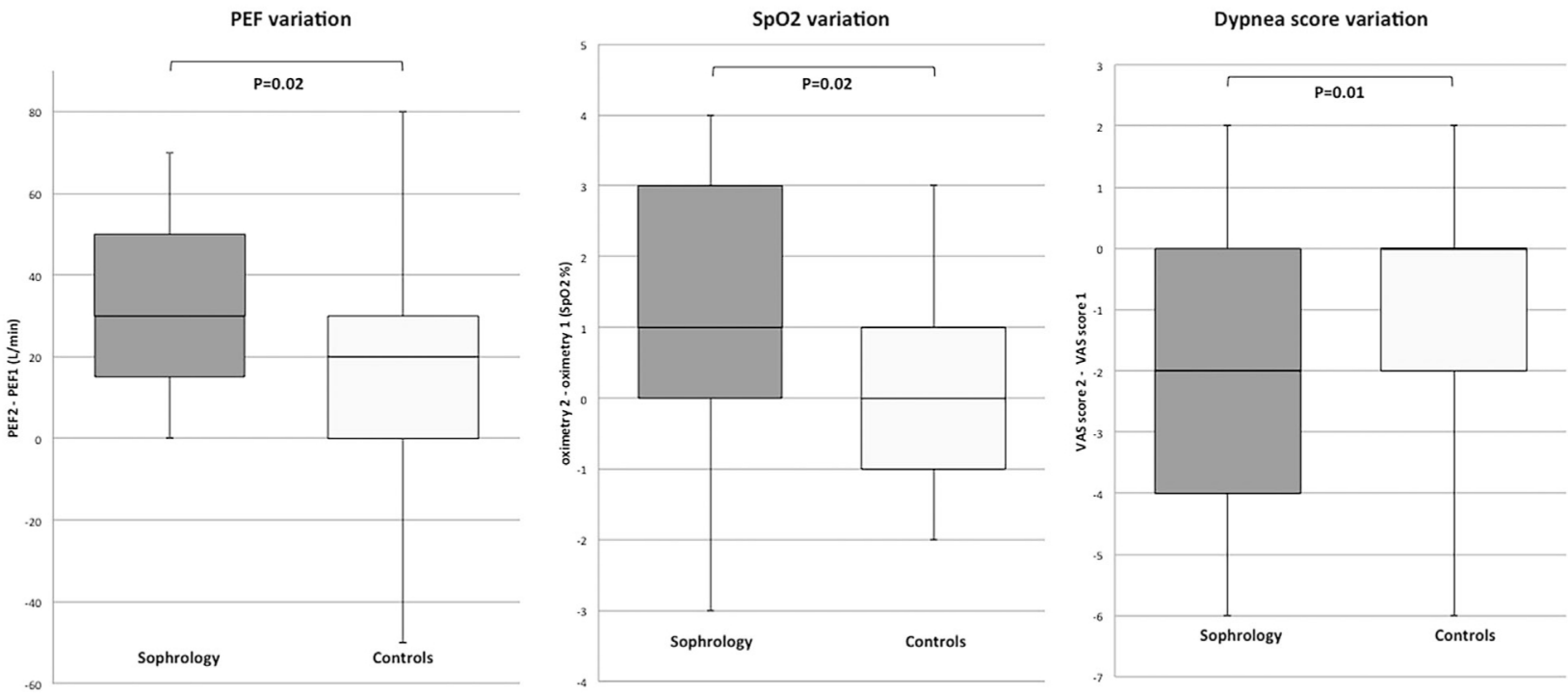

FIGURE 1 Variation between baseline and final evaluation: comparison of the two groups. Box plots of the variation of peak expiratory flow (PEF), dyspnea score, and oxygen saturation (SpO2). The bottom and top of the box represent the 25th and 75 th percentiles, the band inside the box represents the 50th percentile (median), and the end of the whiskers represents the 5 th and 95 th percentiles. $P$-values indicate comparison of the variation between sophrology and control groups 
TABLE 3 Quality of life scores

\begin{tabular}{|c|c|c|c|c|c|c|c|c|c|c|c|}
\hline \multicolumn{2}{|l|}{ Self-reports } & \multicolumn{2}{|l|}{ Sophrology } & \multicolumn{2}{|l|}{ Controls } & \multicolumn{2}{|l|}{ Self-reports } & \multicolumn{2}{|l|}{ Sophrology } & \multicolumn{2}{|l|}{ Controls } \\
\hline Overall & $N$ & Mean ( $\pm S D)$ & $N$ & Mean ( \pm SD) & $P$ value & 13-18 years-old & $N$ & Mean $( \pm S D)$ & $N$ & Mean ( \pm SD) & $P$ value \\
\hline School & 37 & $67.7( \pm 15.2)$ & 35 & $68.4( \pm 15.5)$ & 0.30 & School & 5 & $51.0( \pm 13.9)$ & 4 & $71.3( \pm 19.3)$ & 0.11 \\
\hline Emotion & 37 & $69.9( \pm 15.6)$ & 35 & $65.7( \pm 20.4)$ & 0.33 & Emotion & 5 & $67.0( \pm 16.8)$ & 4 & $38.8( \pm 4.8)$ & 0.01 \\
\hline Physical & 37 & $76.8( \pm 16.0)$ & 35 & $79.3( \pm 16.8)$ & 0.38 & Physical & 5 & $75.6( \pm 16.4)$ & 4 & $69.5( \pm 14.3)$ & 0.58 \\
\hline Psychosocial & 37 & $70.4( \pm 11.9)$ & 35 & $70.2( \pm 14.3)$ & 0.94 & Psychosocial & 5 & $63.7( \pm 10.8)$ & 4 & $58.8( \pm 9.3)$ & 0.49 \\
\hline Relation & 37 & $76.5( \pm 14.3)$ & 35 & $76.6( \pm 21.6)$ & 0.51 & Relation & 5 & $73.0( \pm 8.4)$ & 4 & $66.3( \pm 32.0)$ & 0.66 \\
\hline Health & 37 & $76.8( \pm 16.0)$ & 35 & $79.3( \pm 16.8)$ & 0.38 & Health & 5 & $75.6( \pm 16.4)$ & 4 & $69.5( \pm 14.3)$ & 0.58 \\
\hline Total & 37 & $72.6( \pm 12.1)$ & 35 & $73.4( \pm 13.7)$ & 0.80 & Total & 5 & $67.8( \pm 12.1)$ & 4 & $62.5( \pm 19.8)$ & 0.50 \\
\hline \multicolumn{6}{|l|}{ Self-reports } & \multicolumn{6}{|l|}{ Proxi-reports } \\
\hline $5-7$ years old & $N$ & Mean $( \pm S D)$ & $N$ & Mean ( $\pm S D)$ & $P$ value & Fathers & $N$ & Mean ( $\pm S D)$ & $N$ & Mean ( $\pm S D)$ & $P$ value \\
\hline School & 19 & $65.8( \pm 16.4)$ & 8 & $73.8( \pm 10.6)$ & 0.22 & School & 9 & $66.1( \pm 25.6)$ & 14 & $73.2( \pm 21.0)$ & 0.47 \\
\hline Emotion & 19 & $72.1( \pm 15.5)$ & 8 & $80.0( \pm 14.1)$ & 0.23 & Emotion & 9 & $73.9( \pm 12.4)$ & 14 & $72.1( \pm 23.8)$ & 0.84 \\
\hline Physical & 19 & $79.9( \pm 15.5)$ & 8 & $93.8( \pm 6.7)$ & 0.02 & Physical & 9 & $85.3( \pm 12.7)$ & 14 & $78.2( \pm 20.7)$ & 0.64 \\
\hline Psychosocial & 19 & $70.5( \pm 12.8)$ & 8 & $75.8( \pm 8.7)$ & 0.29 & Psychosocial & 9 & $73.7( \pm 14.1)$ & 14 & $76.8( \pm 18.8)$ & 0.68 \\
\hline Relation & 19 & $73.7( \pm 15.7)$ & 8 & $73.8( \pm 16.9)$ & 0.99 & Relation & 9 & $81.1( \pm 12.7)$ & 14 & $85.0( \pm 23.0)$ & 0.15 \\
\hline Health & 19 & $79.9( \pm 15.5)$ & 8 & $93.8( \pm 6.7)$ & 0.02 & Health & 9 & $85.3( \pm 12.7)$ & 14 & $78.2( \pm 20.7)$ & 0.64 \\
\hline Total & 19 & $73.8( \pm 12.6)$ & 8 & $82.1( \pm 6.3)$ & 0.09 & Total & 9 & $77.7( \pm 12.8)$ & 14 & $77.3( \pm 18.9)$ & 0.95 \\
\hline \multicolumn{6}{|l|}{ Self-reports } & \multicolumn{6}{|l|}{ Proxi-reports } \\
\hline $8-12$ years old & $N$ & Mean ( \pm SD) & $N$ & Mean $( \pm S D)$ & $P$ value & Mothers & $N$ & Mean ( $\pm \mathrm{SD})$ & $N$ & Mean ( \pm SD) & $P$ value \\
\hline School & 13 & $68.5( \pm 11.4)$ & 23 & $66.1( \pm 16.3)$ & 0.65 & School & 28 & $61.7( \pm 20.1)$ & 23 & $67.8( \pm 20.6)$ & 0.29 \\
\hline Emotion & 13 & $67.9( \pm 16.1)$ & 23 & $65.4( \pm 19.2)$ & 0.70 & Emotion & 28 & $62.2( \pm 17.2)$ & 23 & $63.3( \pm 18.5)$ & 0.82 \\
\hline Physical & 13 & $72.6( \pm 16.9)$ & 23 & $76.0( \pm 17.1)$ & 0.52 & Physical & 28 & $76.6( \pm 19.4)$ & 23 & $81.5( \pm 18.4)$ & 0.38 \\
\hline Psychosocial & 13 & $72.8( \pm 10.8)$ & 23 & $70.2( \pm 15.7)$ & 0.60 & Psychosocial & 28 & $67.0( \pm 13.7)$ & 23 & $70.1( \pm 17.1)$ & 0.47 \\
\hline Relation & 13 & $81.9( \pm 13.2)$ & 23 & $79.3( \pm 21.4)$ & 0.96 & Relation & 28 & $77.0( \pm 20.3)$ & 23 & $79.1( \pm 22.9)$ & 0.56 \\
\hline Health & 13 & $72.6( \pm 16.9)$ & 23 & $76.0( \pm 17.1)$ & 0.52 & Health & 28 & $76.6( \pm 19.4)$ & 23 & $81.5( \pm 18.4)$ & 0.38 \\
\hline Total & 13 & $72.7( \pm 11.8)$ & 23 & $72.2( \pm 14.7)$ & 0.92 & Total & 28 & $70.3( \pm 13.5)$ & 23 & $74.1( \pm 15.9)$ & 0.36 \\
\hline
\end{tabular}

randomized into the sophrology group. This likely reflects the evolution of society towards alternative non-invasive therapies. ${ }^{13}$

The primary outcome of this trial, that is the PEF, improved by $30 \mathrm{~L} / \mathrm{min}$ on average, after a single session of sophrology, significantly more than in the control group. At baseline, both groups were statistically not different in any of the measured variables; therefore this result appears as scientifically relevant.

Asthma attacks are multifactorial, and relaxation techniques seem to positively interact between stress, and bronchospasm. Indeed, the controlled clinical trial from Vasquez et $\mathrm{al}^{8}$ showed a significant impact of a relaxation program on both the PEF and the duration of the asthma attack, in comparison to a standard self-management program. The other rare existing controlled clinical trials are in line with our results, even though they did not measure any quantitative physiological outcomes: Chiang et $\mathrm{al}^{6}$ found that relaxation-breathing training decreased anxiety and asthma signs or symptoms in children with moderate-to-severe asthma; and Vedanthan et al ${ }^{44}$ measured in a randomized controlled trial a higher relaxation and positive attitude in university students with asthma who practiced yoga.
The dyspnea score after the sophrology session decreased significantly by two points out of 10 on average, in comparison with no change in the control group. This result is in line with that of our primary outcome. Indeed, the level of dyspnea measured with a visual analogue scale probably stands as a simple surrogate of the PEF. The oxygen saturation also increased in the sophrology group, by $1 \%$ on average, while no change occurred in the control group. This result was statistically significant, however, we need to admit that it is not clinically relevant.

Sophrology focuses on breathing and body movements in the context of tension and relaxation. The asthma attack, from a sophrologist's point of view, represents a sudden physiological disorganization against which one can mentally and bodily interact. ${ }^{16}$ We may hypothesize that sophrology facilitates the relaxation of bronchial smooth muscles and the elimination of bronchial mucus. Added to the conventional therapy using corticosteroids and bronchodilators, sophrology might contribute to improve expiratory physiological capacities. As a result, the PEF increases, the feeling of dyspnea decreases, and the gas exchange ameliorates. 
Unfortunately, the quality of life scores were not significantly higher in the sophrology group than in the control group, at the end of the hospitalization. Usually, patient reported outcomes require larger cohorts to be statistically modified, as reported in our previous quality of life studies. $^{45}$

Unsurprisingly, we found no difference between the two groups in terms of use or doses of conventional medical treatment, that is oxygen, corticosteroids, and bronchodilators. Sophrology appears to be an interesting adjuvant therapy for asthma but we would not recommend using it as an "alternative" therapy. Indeed, the level of evidence of the effectiveness of pharmaceutical treatments for asthma is clear, and neither sophrology nor any other non-pharmaceutical therapy should claim to replace them. ${ }^{41}$ Nevertheless, that does not forbid us to "look beyond the guidelines." 46 In the adult asthma population, some interest has been recently shown for other nonpharmacologic therapies, such as pulmonary rehabilitation, focused breathing techniques, and bronchial thermoplasty, but these techniques are not fully adapted to children. ${ }^{47}$ Therefore, in the pediatric population, we suggest using sophrology as an adjuvant therapy to current guideline-based treatment for asthma.

\section{1 | Study limitations}

Inherently, this type of study cannot be carried out with complete blindness, however the biases have been limited, as the physical therapists have not modified their usual practices during the clinical trial. Moreover, the sophrologists have not been involved in the outcomes' assessment.

The results of this study apply to a population of hospitalized children, where the severity of asthma and the level of stress are, by definition, expected to be high. It would therefore be interesting to evaluate sophrology in the outpatient population, during consultations, or therapeutic education sessions. Moreover, a high number of eligible children did not participate in the study because of logistic issues; indeed, our sophrologists were not only dedicated to the research, and many children were hospitalized during the weekends, when the investigators were not available.

Finally, only one session of sophrology was performed during this study, whereas several sessions are usually necessary in actual practice. Therefore, we plan to conduct a study measuring the impact of a full sophrology program on the quality of life of children with chronic diseases.

\section{5 | CONCLUSION}

This randomized controlled clinical trial assessed, for the first time, the impact of sophrology on asthma in a cohort of 74 hospitalized children. When added to the conventional therapy, one session of sophrology significantly improved the peak expiratory flow, the oxygenation, and the feeling of dyspnea. This study shows the promise of sophrology as a new adjuvant therapy to current guideline-based treatment for asthma in the pediatric population. Further studies using a complete sophrology program among non-hospitalized children and measuring their quality of life, should be considered.

\section{ACKNOWLEDGMENT}

The French National Nursing and Paramedical Clinical Research Program (PHRIP) funded this work. (Ministère des Affaires Sociales et de la Santé).

\section{CONFLICTS OF INTEREST}

The authors declare no conflicts of interest.

\section{ORCID}

Pascal Amedro (iD http://orcid.org/0000-0003-3649-0294

\section{REFERENCES}

1. Nowobilski R, Plaszewski M, Wloch T, Mika P, Gajewski P, Brozek JL. Physiotherapy in asthma-seeking consensus. J Asthma. 2013;50:681-686.

2. Bruurs ML, van der Giessen $L J$, Moed $H$. The effectiveness of physiotherapy in patients with asthma: a systematic review of the literature. Respir Med. 2013;107:483-494.

3. Walsh BK, Hood K, Merritt G. Pediatric airway maintenance and clearance in the acute care setting: how to stay out of trouble. Respir Care. 2011;56:1424-1440. Discussion 1440-1424.

4. Anbar RD. Self-hypnosis for management of chronic dyspnea in pediatric patients. Pediatrics. 2001;107:E21.

5. Hackman RM, Stern JS, Gershwin ME. Hypnosis and asthma: a critical review. J Asthma. 2000;37:1-15.

6. Chiang LC, Ma WF, Huang JL, Tseng LF, Hsueh KC. Effect of relaxation-breathing training on anxiety and asthma signs/symptoms of children with moderate-to-severe asthma: a randomized controlled trial. Int J Nurs Stud. 2009;46:1061-1070.

7. Chitano P, Murphy TM. Maturational changes in airway smooth muscle shortening and relaxation. Implications for asthma. Respir Physiol Neurobiol. 2003;137:347-359.

8. Vazquez MI, Buceta JM. Effectiveness of self-management programmes and relaxation training in the treatment of bronchial asthma: relationships with trait anxiety and emotional attack triggers. J Psychosom Res. 1993;37:71-81.

9. Richter R, Dahme B. Bronchial asthma in adults: there is little evidence for the effectiveness of behavioral therapy and relaxation.J Psychosom Res. 1982;26:533-540.

10. Hock RA, Bramble J, Kennard DW. A comparison between relaxation and assertive training with asthmatic male children. Biol Psychiatry. 1977;12:593-596.

11. Alexander AB, Miklich DR, Hershkoff $H$. The immediate effects of systematic relaxation training on peak expiratory flow rates in asthmatic children. Psychosom Med. 1972;34:388-394.

12. Field T, Henteleff T, Hernandez-Reif M, et al. Children with asthma have improved pulmonary functions after massage therapy. J Pediatr. 1998;132:854-858.

13. Andrews L, Lokuge S, Sawyer M, Lillywhite L, Kennedy D, Martin J. The use of alternative therapies by children with asthma: a brief report. J Paediatr Child Health. 1998;34:131-134.

14. Vazquez I, Buceta J. Relaxation therapy in the treatment of bronchial asthma: effects on basal spirometric values. Psychother Psychosom. 1993;60:106-112.

15. Erskine-Milliss J, Schonell M. Relaxation therapy in asthma: a critical review. Psychosom Med. 1981;43:365-372.

16. de Vicente P, Posada JL. [Medical sophrology and yoga respiration in the physiotherapy of bronchial asthma]. Allergol Immunopathol (Madr). 1978;6:297-310. 
17. Peters TE, Fritz GK. Psychological considerations of the child with asthma. Child Adolesc Psychiatr Clin N Am. 2010;19:319-333. ix.

18. Costa Mdo R, Oliveira MA, Santoro IL, Juliano Y, Pinto JR, Fernandes AL. Educational camp for children with asthma. J Bras Pneumol. 2008;34:191-195.

19. Shaw A, Noble A, Salisbury C, Sharp D, Thompson E, Peters TJ. Predictors of complementary therapy use among asthma patients: results of a primary care survey. Health Soc Care Community. 2008;16:155-164.

20. Yorke J, Fleming SL, Shuldham C. A systematic review of psychological interventions for children with asthma. Pediatr Pulmonol. 2007;42:114-124.

21. Lefevre F. The importance of psychology in a breathing school. Soins Pediatr Pueric. 2006;232:27-29.

22. Tokem $Y$. The use of complementary and alternative treatment in patients with asthma. Tuberk Toraks. 2006;54:189-196.

23. Yorke J, Fleming S, Shuldham C. Psychological interventions for children with asthma. Cochrane Database Syst Rev. 2005;4:CD003272.

24. Alexander AB, Cropp GJ, Chai H. Effects of relaxation training on pulmonary mechanics in children with asthma. J Appl Behav Anal. 1979;12:27-35.

25. Hock RA, Rodgers CH, Reddi C, Kennard DW. Medico-psychological interventions in male asthmatic children: an evaluation of physiological change. Psychosom Med. 1978;40:210-215.

26. Darlas F. 10 asthmatic children treated by psychotherapeutic relaxation (Schultz-Sapiz method from adapted psychanalytic inspiration. Bronches. 1973;23:235-241.

27. Alexander $A B$. Systematic relaxation and flow rates in asthmatic children: relationship to emotional precipitants and anxiety. J Psychosom Res. 1972;16:405-410.

28. Long KA, Ewing LJ, Cohen S, et al. Preliminary evidence for the feasibility of a stress management intervention for 7- to 12-year-olds with asthma. J Asthma. 2011;48:162-170.

29. Gaide M, Surdej F, Daoud-Carrera C, Dudoit E, Duffaud F, Salas S. Sophrology for developing strategies to help patients adapt to cancer treatments. Rev Infirm. 2017;66:37-39.

30. Barre C, Falcou MC, Mosseri V, Carrie S, Dolbeault S. Sophrology for patients in oncology. Soins. 2015;800:17-20.

31. Tocheport P. Sophrology in geriatrics, an innovative approach to reducing pain and anxiety. Soins. 2012;763:16-20.

32. Lavand'homme P, Roelants F. Patient-controlled intravenous analgesia as an alternative to epidural analgesia during labor: questioning the use of the short-acting opioid remifentanil. Survey in the French part of Belgium (Wallonia and Brussels). Acta Anaesthesiol Belg. 2009;60:75-82.

33. Tournaire $M$, Theau-Yonneau A. Complementary and alternative approaches to pain relief during labor. Evid Based Complement Alternat Med. 2007;4:409-417.
34. Baldinelli L, Dall'Oppio L, Bernabeo MC, Cetrullo L. Sophrology in dentistry. G Anest Stomatol. 1986;15:25-28.

35. Constantin JM, Perbet S, Futier E, et al. [Impact of sophrology on noninvasive ventilation tolerance in patients with acute respiratory failure. Ann Fr Anesth Reanim. 2009;28:215-221.

36. Callahan KA, Panter TM, Hall TM, Slemmons M. Peak flow monitoring in pediatric asthma management: a clinical practice column submission. J Pediatr Nurs. 2010;25:12-17.

37. Jones D. Predicted values for peak flow rates. N Z Med J. 1993;106:66.

38. Hicks CL, von Baeyer CL, Spafford PA, van Korlaar I, Goodenough B. The Faces Pain Scale-Revised: toward a common metric in pediatric pain measurement. Pain. 2001;93:173-183.

39. Varni JW, Seid M, Kurtin PS. PedsQL 4.0: reliability and validity of the Pediatric Quality of Life Inventory version 4.0 generic core scales in healthy and patient populations. Med Care. 2001;39:800-812.

40. Tessier S, Vuillemin A, Lemelle J-L, Briancon S. Psychometric properties of the french pediatric quality of life inventory version 4.0 (PedsQL ${ }^{\mathrm{TM}}$ 4.0) generic core scales. Eur Rev Appl Psychol. 2009;59:291-300.

41. Reddel HK, Levy ML. Global Initiative for Asthma Scientific C, Dissemination, Implementation C. The GINA asthma strategy report: what's new for primary care? NPJ Prim Care Respir Med. 2015;25:15050.

42. Schatz M, Sorkness CA, Li JT, et al. Asthma Control Test: reliability, validity, and responsiveness in patients not previously followed by asthma specialists. J Allergy Clin Immunol. 2006;117:549-556.

43. Nathan RA, Sorkness CA, Kosinski M, et al. Development of the asthma control test: a survey for assessing asthma control. J Allergy Clin Immunol. 2004;113:59-65.

44. Vedanthan PK, Kesavalu LN, Murthy KC, et al. Clinical study of yoga techniques in university students with asthma: a controlled study. Allergy Asthma Proc. 1998;19:3-9.

45. Amedro P, Dorka R, Moniotte S, et al. Quality of life of children with congenital heart diseases: a multicenter controlled cross-Sectional study. Pediatr Cardiol. 2015;36:1588-1601.

46. Pike KC, Levy ML, Moreiras J, Fleming L. Managing problematic severe asthma: beyond the guidelines. Arch Dis Child. 2017. [Epub ahead of print].

47. Hall C, Nici L, Sood S, ZuWallack R, Castro M. Nonpharmacologic therapy for severe persistent asthma. J Allergy Clin Immunol Pract. 2017;5:928-935. 